\title{
MANFAAT SKORING PROGNOSTIK DALAM PENENTUAN TATA LAKSANA KASUS METASTASIS OTAK
}

\author{
CLINICAL UTILITY OF PROGNOSTIC SCORES TO GUIDE THE \\ MANAGEMENT OF BRAIN METASTASES
}

Yunni Diansari*

\begin{abstract}
Metastatic brain tumors are the most common intracranial neoplasms in adults and associated with significant morbidity and mortality. The current therapeutic options include surgery, whole brain radiation therapy (WBRT), stereotactic radiation (SRS), systemic therapy and symptom management only. The goals of brain metastasis management are giving longer survival, if possible the improvement in neurologic deficit and a better quality of life. Prognostic scores, a useful tool for BM patients, as an estimation of a patient's prognosis can guide the tailored treatment for these patients. A more aggressive approaches is recommended in patients with good performance state with and controlled systemic disease. While palliative management is focused to patients on terminal state or with other comorbid disease. A number of prognostic scoring systems for BM patients have been proposed are Recursive Partitioning Analysis (RPA), the Score Index for Radiosurgery (SIR), the Basic Score for Brain Metastases (BSBM) and the Graded Prognostic Assessment (GPA). Recursive Partitioning Analysis and GPA are able to be implemented in brain metastatic patient in Indonesia.
\end{abstract}

Keyword: Brain metastatic, prognostic scores, survival rate

\section{ABSTRAK}

Tumor otak metastasis merupakan tumor intrakranial yang paling sering dijumpai dan menyebabkan morbiditas serta mortalitas yang bermakna. Pilihan tata laksana terdiri dari tindakan bedah, whole brain radiation therapy (WBRT), sterotactic radiosurgery (SRS), terapi sistemik atau tata laksana simtomatik saja. Tujuan tata laksana pada pasien dengan metastasis otak adalah memperpanjang survival jika memungkinkan dengan mengontrol defisit neurologis dan memberikan kualitas hidup yang baik. Skoring prognostik merupakan metode yang bermanfaat pada kasus metastasis otak, karena dengan dapat memperkirakan prognosis pasien maka dapat menentukan pilihan tata laksana yang tepat. Tata laksana agresif direkomendasikan pada penderita dengan status performance yang baik dan penyakit sistemik yang terkontrol. Adapun tata laksana paliatif ditujukan pada pasien dengan kondisi terminal atau ada komorbid lain yang menyertai. Beberapa skoring prognostik telah diajukan seperti, Recursive Partitioning Analysis (RPA), Score Index For Radiosurgery (SIR), Basic Score for Brain Metastases (BSBM), dan Graded Prognostic Assessment (GPA). Recursive Partitioning Analysis dan GPA merupakan pilihan yang dapat diterapkan pada populasi pasien metastasis otak di Indonesia.

Kata kunci: Metastasis otak, skoring prognostik, survival rate

*Departemen Neurologi FK Universitas Sriwijaya/RSUP Dr. Mohammad Hoesin, Palembang. Korespondensi: yunni.diansari@gmail.com.

\section{PENDAHULUAN}

Metastasis otak merupakan komplikasi neurologi paling serius pada pasien dengan keganasan sistemik yang dapat menyebabkan mortalitas dan morbiditas yang bermakna. Metastasis otak bahkan merupakan jenis tumor intrakranial yang paling sering dijumpai dibandingkan dengan tumor primer. ${ }^{1}$ Diperkirakan insidens metastasis otak berkisar 9-50\% pada penderita dengan keganasan ${ }^{2-6,9}$ atau 100.000170.000 populasi terdiagnosis metastasis otak setiap tahunnya. ${ }^{4}$ Insidens ini 3-10 kali lebih tinggi dibandingkan tumor primer otak setiap tahunnya., ${ }^{4,6}$ Di Amerika Serikat diperkirakan bervariasi dari 21.000 sampai 400.000 per tahun. ${ }^{2} \mathrm{Di}$ Indonesia sendiri belum ada penelitian yang mempublikasikan tentang angka kejadian dan survival rate pada pasien metastasis otak.

Penegakan diagnosis metastasis otak memberikan dampak yang sangat besar terhadap survival rate serta pilihan terapi yang rasional. Secara statistik, overall survival rate pasien metastasis otak tidaklah panjang, rerata tidak lebih dari 6 bulan. ${ }^{3,7}$ Namun jika tidak ditatalaksana, median survivalnya hanya berkisar 1 bulan, ${ }^{8}$ walaupun beberapa kelompok memiliki kemungkinan survival yang lebih panjang. .,7 $^{4}$

Tata laksana metastasis otak sendiri masih merupakan tantangan di bidang onkologi dengan tujuan survival yang lebih panjang, perbaikan kualitas hidup serta stabilisasi fungsi neurokognitif. Pilihan 
tata laksana meliputi tindakan bedah, radioterapi berupa WBRT (whole brain radiotherapy) atau SRS (stereotactic radiosurgery), terapi sistemik, maupun tata laksana simtomatik terhadap gejala yang timbul. Tindakan bedah dan SRS dapat memberikan kontrol lokal yang cukup panjang untuk lesi yang tunggal atau sedikit. Kombinasi dengan WBRT merupakan pilihan terbaik untuk mengontrol secara keseluruhan, namun kombinasi tersebut dapat menjadi tata laksana yang berlebihan pada pasien dengan survival yang pendek. $^{8-11}$

Oleh karena itu, skoring prognostik merupakan metode yang bermanfaat untuk membantu klinisi dalam memilih terapi yang tepat pada pasien dengan metastasis otak. Dengan mengetahui perkiraan survival rate seorang pasien, dapat ditentukan pilihan tata laksana selanjutnya. Pada pasien dengan status performance yang baik dan tumor primer yang terkontrol direkomendasikan tata laksana yang lebih agresif. Tata laksana paliatif dilakukan untuk mengatasi gejala pada kondisi penyakit yang sudah lanjut ataupun ada kondisi komorbid yang tidak memungkinan untuk dilakukan tindakan agresif.

\section{PEMBAHASAN}

National Cancer Institute (NCI) mendefinisikan faktor prognostik sebagai situasi atau kondisi, atau karakteristik pasien yang dapat digunakan untuk memperkirakan kesempatan untuk mengalami perbaikan dari suatu penyakit atau kemungkinan penyakit itu kambuh kembali. ${ }^{12}$ Indikator prognostik telah digunakan pada berbagai keganasan untuk mengetahui prognosis pasien dan sebagai alat bantu dalam membuat keputusan terapi. ${ }^{3}$ Skoring prognostik juga berperan penting dalam penentuan pasien, pengelompokan, randomisasi, dan dapat membantu untuk memperkirakan survival pasien. Dengan menggunakan skoring prognostik, dapat membantu perhitungan efektivitas biaya dengan kemungkinan harapan hidup pasien.

Ada berbagai faktor yang mungkin berpengaruh terhadap luaran pasien metastasis otak yang dapat dijadikan faktor prognosis tanpa memperhitungkan tata laksana yang akan diberikan, meliputi kondisi pasien, status tumor primer dan sistemik, serta karakteristik lesi metastasis itu sendiri. Faktor yang dianggap berpengaruh adalah usia, status performance, ada tidaknya metastasis ekstrakranial yang lain, status tumor primer, dan jumlah lesi metastasis. ${ }^{3,5,7-8}$

Saat ini terdapat skoring prognostik yang didasarkan pada penelitian berbasis data retrospektif di beberapa negara dengan berbagai karakteristik klinis pasien metastasis otak, antara lain Recursive Partitioning Analysis (RPA), Scoring Index for Radiosurgery (SIR), Basic Score for Brain Metastasis (BSBM), dan Graded Prognostic Score (GPA). Setiap skoring memiliki kelebihan dan keterbatasan masing-masing, serta sebagian telah dilakukan validasi. ${ }^{3,5,8,13-16}$

Recursive Partitioning Analysis merupakan sistem skoring yang cukup sederhana dengan indikator yang mudah diterapkan. Skoring ini dibuat oleh Gaspar dkk berdasarkan analisis pada data retrospektif yang cukup besar dari 3 penelitian Radiation Therapy Oncology Group (RTOG) dari tahun 1979 sampai 1993. Karakteristik variabel terdiri dari variabel yang berkaitan dengan pasien (usia, Karnofsky Performance Scale/KPS, fungsi neurologis, defisit neurologis) serta variabel yang berkaitan dengan tumor (patologi tumor primer, status tumor primer, ada tidaknya metastasis ekstrakranial, jumlah lesi, interval antara diagnosis primer sampai dengan timbulnya metastasis otak). Faktor yang berkaitan dengan tata laksana juga dipertimbangan dalam analisis ini. Semua subjek menjalani WBRT pada penelitian ini.

Terdapat 21 variabel yang dimasukkan pada analisis awal untuk menentukan faktor prognosis yang akhirnya menjadi 4 karakteristik sebagai acuan faktor prognostik, yaitu usia, KPS, status tumor primer, dan metastasis ekstrakranial (Tabel 1). ${ }^{13}$

Skoring SIR diajukan oleh Weltman dkk melalui analisis 65 data retrospektif yang diperoleh dari data satu institusi. Dari semua subjek metastasis otak yang menjalani SRS baik sebagai tata laksana awal atau remisi, didapatkan faktor yang berpengaruh terhadap prognosis, yaitu usia, KPS, status penyakit sistemik, jumlah lesi, dan volume lesi terbesar (Tabel 
2). Perbedaan sistem ini adalah dimasukkannya volume lesi yang mungkin dilakukan jika pasien akan menjalani SRS. Skoring SIR ini lebih akurat dalam memperkirakan survival dan luaran pada pasien metastasis otak yang menjalani tindakan SRS. ${ }^{14}$

\begin{tabular}{cl} 
Tabel 1. & $\begin{array}{l}\text { Skoring Prognostik Recursive Partitioning } \\
\text { Analysis }\end{array}$ \\
\hline Kelas & \multicolumn{1}{c}{ Variabel } \\
\hline I & - Usia $<65$ tahun, \\
& - KPS $\geq 70$ \\
& - Tumor primer terkontrol \\
& - Tidak ada metastasis ekstrakranial \\
II & - Semua kondisi yang tidak termasuk kelas I \\
& dan III \\
III & - KPS $<70$ \\
\hline
\end{tabular}

KPS: Karnofsky Performance Scale.

Skoring BSBM diperkenalkan oleh Lorenzoni dkk berdasarkan analisis 110 pasien metastasis analisis akhir didapatkan 3 faktor yang berpengaruh, yaitu KPS, status tumor primer, serta adanya metastasis ekstrakranial (Tabel 3).

Tabel 4. Skoring Prognostik Graded Prognostic Score

\begin{tabular}{lccc}
\hline \multirow{2}{*}{ Variabel } & \multicolumn{3}{c}{ Nilai } \\
\cline { 2 - 4 } & $\mathbf{0}$ & $\mathbf{0 , 5}$ & $\mathbf{1 , 0}$ \\
\hline Usia & $>60$ & $50-59$ & $<50$ \\
KPS & $<70$ & $70-80$ & $90-100$ \\
Jumlah lesi otak & $>3$ & $2-3$ & 1 \\
Metastasis ekstrakranial & Ada & - & Tidak ada \\
\hline
\end{tabular}

KPS: Karnofsky Performance Scale; Nilai 0, 0.5 dan 1 diberikan pada setiap kategori. Total nilai merupakan hasil penjumlahan nilai pada setiap kategori dengan kisaran 0 sampai 4. GPA kelas I: 3,5-4, Kelas II: 3, Kelas III: 2-2,5, Kelas IV: 0-1.

Graded Prognostic Score merupakan sistem skoring yang diajukan oleh Sperduto dkk berdasarkan analisis 1960 pasien dari data dasar RTOG yang lebih lengkap. ${ }^{16}$ Graded Prognostic Score ini dianggap

Tabel 2. Skoring Prognostik Scoring Index for Radiosurgery

\begin{tabular}{|c|c|c|c|}
\hline \multirow{2}{*}{ Variabel } & \multicolumn{3}{|c|}{ Nilai } \\
\hline & $\mathbf{0}$ & 1 & 2 \\
\hline Usia & $\geq 60$ & $51-59$ & $\leq 50$ \\
\hline KPS & $\leq 50$ & $60-70$ & $80-100$ \\
\hline Status penyakit sistemik & Progresif & Stabil atau remisi parsial & Remisi lengkap atau tidak ada bukti penyakit \\
\hline Jumlah lesi & $\geq 3$ & 2 & 1 \\
\hline Volume lesi terbesar $\left(\mathrm{cm}^{3}\right)$ & $>13$ & $5-13$ & $<5$ \\
\hline
\end{tabular}

Nilai 0,1,2 diberikan pada setiap kategori; Total nilai merupakan hasil penjumlahan dari semua kategori dengan kisaran 0-10; SIR kelas I: 8-10. Kelas II: 4-7. Kelas III: 1-3.

otak yang menjalani SRS dan sebagian kombinasi dengan WBRT dari tahun 1999 sampai 2003 pada satu institusi. Penelitian awal ditujukan untuk menilai efek SRS terhadap survival pasien dan membandingkannya dengan dua sistem yang telah ada (RPA dan SIR). Follow up dilakukan 2 sampai 32 bulan, terdapat $56 \%$ pasien yang masih hidup. Pada

Tabel 3. Skoring Prognostik Basic Score for Brain Metastasis

\begin{tabular}{lcc}
\hline \multirow{2}{*}{ Variabel } & \multicolumn{2}{c}{ Nilai } \\
\cline { 2 - 3 } & $\mathbf{0}$ & $\mathbf{1}$ \\
\hline KPS & $\leq 70$ & $80-100$ \\
Kontrol terhadap tumor primer & Tidak & ya \\
Metastasis ekstrakranial & Ya & Tidak \\
\hline
\end{tabular}

KPS: Karnofsky Performance Scale; Nilai 0 dan 1 diberikan pada setiap kategori. Nilai total merupakan hasil penjumlahan dari nilai setiap kategori dengan kisaran 0 sampai 3; BSBM kelas I: 3, Kelas II :2, Kelas III: 1, Kelas IV: 0. dapat memperbaiki kekurangan sistem skoring sebelumnya berdasarkan data kohort yang cukup besar dibandingkan skoring lain. Pada GPA jumlah lesi dimasukkan sebagai salah satu indikator yang tidak diperhitungkan pada RPA dan BSBM. Berbagai penelitian sebelumnya menunjukkan jumlah lesi berkaitan dengan survival, yaitu lesi tunggal memiliki prognosis yang lebih baik. Sebaliknya skoring GPA tidak memasukkan status tumor primer, karena dianggap subjektif penilaiannya, serta tidak memperhitungkan volume lesi. Adapun indikator yang diperhitungkan pada skoring GPA terdapat pada Tabel $4 .^{16}$

Tabel 5 menunjukkan perbandingan median survival pada beberapa skoring. Pada skoring ini, penderita dikelompokkan dalam tiga kelas, yaitu RPA kelas I memiliki median survival paling baik 
Tabel 5. Perbandingan Median Survival Beberapa Skoring Prognostik

\begin{tabular}{ccccc}
\hline \multirow{2}{*}{ Kelas } & \multicolumn{4}{c}{ Median Survival (Bulan) } \\
\cline { 2 - 5 } & RPA & SIR & BSBM & GPA \\
\hline I & 7,1 & 27,7 & 23 & 11 \\
II & 4,3 & 13,1 & 13,1 & 6,9 \\
III & 2,3 & 4,6 & 3,3 & 3,8 \\
IV & - & - & 1,9 & 2,6 \\
\hline
\end{tabular}

RPA: Recursive Partitioning Analysis; SIR: Scoring Index for Radiosurgery; BSBM: Basic Score for Brain Metastasis; GPA: Graded Prognostic Score.

7,3 bulan. ${ }^{13}$ Skoring SIR mengelompokkan pasien menjadi 3 kelas dengan median survival paling baik pada kelompok SIR I, yaitu 27,7 bulan dan paling buruk pada kelompok SIR III, yaitu 4,3 bulan. ${ }^{14}$

Berdasarkan skoring BSBM, pasien dikelompokkan dalam 4 kelas. Pada BSBM kelas I median survival tidak bisa didapatkan berkaitan dengan sejumlah pasien yang masih hidup pada akhir follow up. Median survival paling pendek pada BSBM kelas IV, yaitu 1,9 bulan. Sistem ini diperbarui lagi pada tahun 2007, yaitu pada kelompok BSBM kelas I dengan total nilai 3 didapatkan median survival 23 bulan. ${ }^{15}$ Pada skoring GPA, pasien dikelompokkan menjadi 3 kelas, dengan perkiraan median survivalnya tidak jauh berbeda dengan RPA (Tabel 5). ${ }^{16}$

Dari berbagai skoring tersebut, RPA dan GPA merupakan pilihan yang dapat diterapkan pada populasi pasien metastasis otak di Indonesia, karena indikator yang dipakai dapat dipenuhi. Selain itu standar tata laksana pada populasi kedua sistem dapat dilakukan pada RS di Indonesia. Recursive Partitioning Analysis 1 dan GPA 1 memperlihatkan perkiraan survival yang cukup panjang, sehingga dapat ditawarkan pilihan terapi maksimal.

Pada kelompok pasien dengan kondisi fisik yang baik, tumor primer yang terkontrol dan jumlah lesi metastasis sedikit (tunggal atau kurang dari 3) pilihan terapi seperti tindakan bedah atau SRS yang dikombinasi dengan WBRT merupakan pilihan yang cukup realistis untuk memperpanjang survival. Sebaliknya pada RPA 3 dan GPA 4 dengan perkiraan median survival tidak lebih dari 4 bulan, maka pertimbangan terapi paliatif merupakan pilihan yang rasional. Tata laksana medikamentosa dengan penggunaan kortikosteroid disertai WBRT diharapkan dapat memberikan perbaikan terhadap defisit neurologis untuk memberikan kualitas hidup lebih baik.

\section{KESIMPULAN}

Sebagian besar penderita metastasis otak memiliki survival yang pendek. Hal ini berkaitan dengan progresivitas penyakit sistemik atau akibat komplikasi neurologi yang tidak terkontrol. Meskipun terapi paliatif cukup efektif, namun pada sebagian penderita metastasis otak didapatkan survival yang cukup panjang dengan tata laksana yang agresif. Skoring prognostik dapat membantu kelompok penderita menentukan pilihan tata laksana yang tepat berdasarkan perkiraan harapan hidupnya.

\section{Tinjauan Pustaka}

1. Welch MR, Kaley TJ. Intracranial metastases. Dalam: Schiff D, Packer RJ, editor. Neuro-oncology. Edisi ke-1. John Wiley \& Sons Ltd. 2012. h. 179-90.

2. Cagney DN, Martin AM, Catalano PJ, Redig AJ, Lin $\mathrm{Nu}$, dkk. Incidence and prognosis of patients with brain metastases at diagnosis of systemic malignancy: a population based study. Neurooncology. 2017;19(11):1511-21.

3. Venur VA, Ahluwaliamm MS. Prognostic scores for brain metastasis patients: use in clinical practice and trial design. Chinese Clin Oncol. 2015;4(2):18.

4. Kong XT, Alexandru D, Bota DA. Epidemiology of central nervous system metastases. Dalam: Hayat MA, editor. Brain metastases from primary tumor. Volume ke-1. Elseviers. 2014. h. 11-23.

5. Miyazawa K, Shikama N, Okazaki S, Koyama $\mathrm{T}$, Takahashi T, Kato S. Predicting prognosis of shaort survival time after palliative whole-brain radiotherapy. J Radiation Res. 2018;59(1):43-9.

6. Soffietti R, Franchino F, Ruda R. Brain metastasis as complication of systemic cancer. Dalam: D. Schiff, Wen PJ, Arillag I, editor. Cancer neurology in clinical practice. Edisi ke-3. Springer International Publishing. 2018. h. 57-80.

7. Stelzer KJ. Epidemiology and prognosis of brain metastasis. Surgical Neurol Intl. 2013;4(4):192-202.

8. Luo J, Zhu H, Tang Y, Wang H, Zhou X, Lu X, dkk. Analysis of prognostic factors and comparison of prognostic index scores in patients with brain metastases after whole brain radiotherapy. Intl J Clin Experimental Med. 2014;7(12):5217-25.

9. Olvera JN, Barahona EA, Liquidano ME, Cobos AM. Brain metastases: literature review. Revista Medica Del Hospital General De Mexico. 2017;80(1):60-6. 
10. Sawaya R, Bindal RK, Lang FF, Suki D . Metastatic brain tumor. Dalam: Kaye AH, Laws ER, editor. Brain tumor an encyclopedic approach. Edisi ke-3. Elsevier. 2012. h. 864-90.

11. Brastianos HC, Cahill DP, Brastianos PK. Systemic therapy of brain metastases. Current Neurol Neurosci Reports. 2015;15(2):518.

12. National Cancer Institute. NCI dictionary of cancer terms; 2015.

13. Gaspar L, Scott C, Rotman M, Asbell S, Phillips T, Wasserman T, dkk. Recursive partitioning analysis (RPA) of prognostic factors in three radiation therapy oncology group (RTOG) brain metastases trials. Intl J Radiation Oncol Biol Physics. 1997;37(4):745-51.
14. Weltman E, Salvajoli JV, Brandt RA, De-MoraisHanriot R, Prisco FE, Cruz JC, dkk. Radiosurgery for brain metastases: a score index for predicting prognosis. Intl J Radiation Oncol Biol Physics. 2000;46(5):1155-61.

15. Lorenzoni J, Devriendt D, Massager N, David P, Ruiz $\mathrm{S}$, Vanderlinden B, dkk. Radiosurgery for treatment of brain metastasis: estimation of patient eligibility using three stratification system. International J Radiation Oncol Biol Physics. 2004;60(1):218-24.

16. Sperduto PW, Berkey B, Gaspar LE, Mehta M, Curran W. A new prognostic index and comparison to three other indices for patients with brain metastases: an analysis of 1960 patients in the RTOG database. Intl J Radiation Oncol Biology Physics. 2008;70(2):510 14. 